\title{
As cidades do telejornalismo: algumas considerações
}

\author{
Alfredo Eurico Vizeu Pereira Junior
}

\begin{abstract}
Resumo: Este trabalho tem como objetivo propor algumas reflexões sobre como diariamente os telejornais vão construindo o que denominamos as "cidades do telejornalismo". Entendemos que os noticiários televisivos ao estabelecerem uma série de enquadramentos e recortes sobre os acontecimentos que ocorrem diariamente contribuem de uma forma relevante para a imagem que construímos das cidades. Na análise, com base em pesquisa que realizamos, vamos nos deter basicamente na construção do Recife como uma cidade violenta.
\end{abstract}

Palavras-chave: Telejornalismo, notícias e construção do real.

Abstract: This paper aims to give some analytical view about how the news on television build up every day the so-called television news' cities. We understand that since the news broadcasting establishes many frames and cuts about the daily events, they contribute in a relevant way for the images we build of the cities. In this analysis, based upon my current research, I will emphasize on the imaginary construction of Recife as a violent city.

Keywords: Television journalism, news and construction of the reality.

Resumen: El presente trabajo tiene como objetivo proponer algunas reflexiones acerca de como los telediarios diariamente construyen lo que llamamos "las ciudades del teleperiodismo". Compreendemos que los diarios televisivos al establecer una serie de encuadres sobre los hechos que ocurren en el cotidiano contribuyen de forma relevante a la imagen que hacemos de las ciudades. En nuestro análisis, con base en una investigación que hemos realizado, nos detendremos basicamente ne la construcción de Recife como una ciudad violenta.

Palavras-clave: teleperiodismo, noticias, construcción de lo real

\section{INTRODUÇÃO}

Os telejornais ocupam um lugar central na forma como os brasileiros percebem o mundo que os cerca. A agenda diária de cobertura dos fatos pelos noticiários influencia a agenda pública. As conseqüências desse agendamento e do enquadramento dos acontecimentos feito pelos noticiários sugerem que eles não só nos propõem sobre o que é que devemos pensar, como também nos propõem como pensar (McCOMBS; SHAW, 1993).

Além disso, no processo de produção da notícia ao selecionarem determinados fatos excluindo outros, os informativos televisivos organizam, sistematizam, classificam e hierarquizam a realidade fazem. Ou seja, os telejornais fazem enquadramentos, constroem molduras, e como artistas desenham as cidades da televisão.

Vice-coordenador do PPGCOM/UFPE. 
Os estudos sobre esse fenômeno estão a exigir do mundo acadêmico, em particular, dos pesquisadores, um olhar mais atento e maiores investigações sobre os telejornais de rede nacional, os noticiários regionais e locais que contribuem de uma forma relevante para a construção de parte da realidade social da realidade brasileira diariamente (BERGER;LUCKMANN,1995 ). A economia, a cultura, a sociedade e as cidades são “moldadas” dentro das regras e normas do campo do telejornalismo.

O objetivo deste trabalho é propor algumas reflexões sobre como diariamente os jornais vão construindo o que denominamos neste trabalho de as cidades do telejornalismo. Ou seja, ao fazerem uma série de recortes sobre o dia-a-dia das cidades os jornais oferecem, aos telelespectadores, audiência comunicativa e interativa - decodifica, estabelece significados, ressignifica, elabora e reelabora as notícias - visões sobre as cidades. Nesse sentido, as imagens transmitidas pelos noticiários funcionam como uma referência para as pessoas perceberem as cidades e identificá-las a partir do que foi veiculado.

É dentro deste contexto que temos a Bahia do carnaval dos trios elétricos, o Recife do maracatu e do frevo, entre outras tipificações que acabam contribuindo para as pessoas conhecerem as cidades. Elas acabam sendo conhecidas só por uma parte de sua realidade que termina representando o todo. É como se no Recife só existisse o maracatu. Entendemos que a reflexão sobre essa questão pode oferecer pistas para entendermos a representação das cidades na mídia nas sociedades democráticas.

Neste estudo tomamos como exemplo para mostrar como os telejornais vão construindo a imagem das cidades uma pesquisa que realizamos com o objetivo de buscar pistas para compreender como os jornalistas contribuem diariamente para a produção social do Recife. Dentro dos limites deste trabalho vamos nos deter basicamente no aspecto que diz respeito à construção do Recife como uma cidade violenta (VIZEU,2006), (PEREIRA, 2006), (WANDERLEY, 2006).

As pesquisas foram realizadas no período 2006-2007 nos telejornais “Cotidiano”, da TV Tribuna, do grupo empresarial João Santos; e no "TV Jornal do Meio-Dia”, da TV Jornal, do Grupo Paes Mendonça. Dois grandes grupos empresariais brasileiros com sede em Pernambuco com interesses em outras áreas como shopping centers, ramo imobiliário, cimento, entre outros. 
Os dados da investigação foram coletados no trabalho de campo, nas redações dos noticiários, através da observação-participante (CASETTI;CHIO; 1999) em que procuramos acompanhar e identificar as rotinas e as práticas jornalísticas na produção da notícia. Também foram realizadas entrevistas semi-estruturadas (THIOLLENT, 1982) com a finalidade de procurar pistas que apontassem quais as estratégias mobilizadas pelos jornalistas na cobertura diária sobre a cidade do Recife.

Nos depoimentos/entrevistas que utilizamos no trabalho os jornalistas não são identificados para preservar sua identidades garantindo assim que se manifestassem sem preocupações de punições suas práticas cotidianas e seu olhar sobre as mesmas. Eles são identificados como apuradores (realizam o levantamento dos fatos que podem ser notícias), editores (fazem a edição das notícias) e editoras-chefe (responsáveis pela chefia do telejornal).

Este artigo é dividido em dois momentos. No primeiro procuramos fazer uma breve contextualização do telejornalismo como um lugar de construção do real e num segundo como cotidianamente os jornalistas, no complexo processo de produção da notícia vão construindo as “cidades da televisão”, as cidades do telejornalismo..

O modelo que apresenta o Jornalismo como um lugar de reprodução do real, como uma espécie de fotografia da realidade, já não encontra praticamente mais guarida nas pesquisas desenvolvidas na área (TRAQUINA, 2004), (SHUDSON, 2002) (PENA, 2005). No entanto, nas redações das empresas jornalísticas e entre os jornalistas, essa visão do campo jornalístico como um espelho da realidade ainda se mantém de uma maneira forte,em função de dois mitos da prática profissional, que são: a imparcialidade e a objetividade, que permitiriam ao jornalista afirmar que o distanciamento dos fatos garantiria a notícia reproduzir o real. (SCHUDSON, 1978).

O processo de produção da notícia é extremamente complexo e envolve desde a captação, elaboração/redação/edição, uma audiência interativa. Envolve momentos de contextualização e descontextualização dos fatos. É resultado da cultura profissional, da organização do trabalho, dos processos produtivos, dos códigos particulares(as regras de redação), da língua e das regras do campo das linguagens, da enunciação jornalística e das práticas jornalísticas.

Além disso - e não menos importante - acontece dentro de contextos sociais, históricos e culturais estruturados. Como bem observou Bourdieu (1997) os jornalistas 
refrataram a realidade ao cobrir os acontecimentos. Ou seja, eles têm “óculos” especiais a partir dos quais vêem certas coisas e não outras: “eles operam uma seleção e uma construção do que é selecionado” [grifo é nosso], (Bourdieu, 1997, p. 25) A notícia ao refratar a realidade constitui e é constituída por essa.

Não pretendemos fazer aqui uma ampla discussão sobre as "teorias construtivistas” da realidade social (CORCUFF, 2001). Interessa-nos, particularmente, chamar a atenção para como o jornalismo contribui para a produção da realidade - para fins deste estudo usaremos no artigo produção, representação e construção de uma forma indistinta. A preocupação central é discutir e refletir o campo jornalístico como um lugar relevante na construção social da realidade (VERÓN, 1995).

Consideram que a imagem que o Jornalismo constrói da realidade é resultado de uma atividade profissional de mediação vinculada a uma organização que se dedica basicamente a interpretar a realidade social e mediar os que fazem parte do espetáculo mundano e o público. Compartilhamos com a afirmação de Gomis (1991) e consideramos que a mídia não só transmite, mas prepara e apresenta uma realidade dentro das normas e das regras do campo jornalístico.

Como argumenta o autor, o que a mídia apresenta não é nem espelho nem janela da realidade e não poderia ser de outra maneira, uma vez em ambos as metáforas não são levadas em conta. No entanto, elas são essenciais para a mídia em particular na produção da notícia. A linguagem permite "fazer presente” uma diversidade de objetos que se acham ausentes do "aqui e agora”.

\section{A ORGANIZAÇÃO BUROCRÁTICA DO MUNDO}

O Jornalismo hoje é essencial para a vida em sociedade. Os telejornais cumprem uma função de sistematizar, organizar, classificar e hierarquizar a realidade. Dessa forma contribuem para uma organização do mundo circundante.

Fishman (1990, p.51) diz que o mundo é burocraticamente organizado pelos jornalistas. De certa forma é o que o editor-chefe de um telejornal faz todos os dias quando organiza o espelho do jornal. Ou seja, a ordem de entrada das matérias que vão ao ar num telejornal. Numa pesquisa que realizamos sobre a definição das notícias num telejornal local observamos que a abertura do noticiário sempre era como uma notícia de impacto do dia; e, no encerramento, as notícias mais leves 
(eventos culturais, mostras, etc.), normalmente, encerravam o informativo televisivo VIZEU (2000).

Hall (2005) explica que na construção das notícias os jornalistas mobilizam enquadramentos conhecidos e fazem alguns ajustes que fazem o velho e o banal parecerem novo. Segundo o autor, as notícias já estão praticamente escritas antes de os jornalistas sentarem nos terminais de computador das redações e redigirem suas matérias.

Chandler (2005) lista alguns procedimentos no processo de produção da notícia num telejornal que mostram que os fatos que vão virar notícias não só selecionados, mas ativamente construídos. Ele observa que ao fim de uma entrevista gravada são feitas imagens de detalhes da entrevista para serem utilizados na edição da fala do entrevistado. O objetivo é ocultar o processo de edição procurando dar um efeito de realidade para a matéria.

Nas investigações que realizamos (VIZEU, 2005); (VIZEU, 2000) observamos que no processo de produção das notícias nos telejornais, os jornalistas/editores realizavam “enquadramentos da realidade”. É o que Tuchmann (1980) mostra na sua pesquisa realizada nos Estados Unidos, durante dez anos, em redações de tv e jornal na qual identifica uma série de recortes que os jornalistas realizam sobre fatos e acontecimentos com o objetivo de transformá-los em notícias dentro das regras e normas estabelecidas pelo campo jornalístico.

Tuchmann (1980) explica que os telejornais utilizam ângulos determinados na produção das reportagens com enquadramentos que buscam conferir significados sociais as relações espaciais. Uma imagem mais próxima procura enfatizar aspectos mais dramáticos da matéria, ocorrendo o contrário quando a imagem é mais geral o que procura transmitir uma espécie de reprodução da realidade, é como se essa estivesse sendo mostrada de uma forma objetiva tal como é, produzindo um efeito de real.

De acordo com a autora, nas práticas diárias os jornalistas fazem um enquadramentos das múltiplas realidades. Um exemplo disso é a tipificação dos acontecimentos em .notícias: “duras” (as factuais do dia. Ex: um acidente de ônibus com mortos); "leves” (shows, peças de teatros, etc. que não precisam ir ao ar no 
telejornal no dia em que foram gravadas porque não perdem atualidade) e "súbitas" (uma ruptura no cotidiano. Ex: acidente de avião).

Além dessas ainda há as notícias “em desenvolvimento” (notícias que vão mudando ao longo do dia em função de novas informações. Ex: uma operação da Polícia Federal para prender fraudadores da Receita Federal); e as notícias "em seqüência” (há um calendário prévio dos acontecimentos. Ex: uma CPI normalmente tem a agenda dos depoimentos da semana).

Tuchmann (1980) afirma que o enquadramento das notícias organiza a realidade cotidiana e é parte importante dessa por causa do caráter público que é uma característica essencial da notícia. Complementa afirmando que a notícia não só define, redefine, constitui e reconstitui significados sociais; mas também define e redefine, constitui e reconstitui maneiras de fazer coisas: os processos existentes e as instituições.

Nesse processo de enquadramento da realidade os jornalistas estabelecem uma “trama de fatos”, a "trama da faticidade”. São os procedimentos e as operações mobilizados no processo de produção da notícia no qual os acontecimenetos são selecionados, definidos e avaliados como "fatos jornalísticos". Ou seja, eles são impelidos a identificar como fatos, interpretações produzidas por determinadas fontes, mas não por outras (TUCHMAN, 1980). Nesse processo de seleção e exclusão os jornalistas vão contribuindo para a construção social da realidade.

\section{AS OPERAÇÕES/CONSTRUÇÕES JORNALÍSTICAS}

As cidades do telejornalismo são construídas dentro desse contexto. Esse processo é realizado cotidianamente através de cinco operações/construções jornalísticas numa releitura de cinco categorias que apresentamos anteriomente mobilizadas pelos jornalistas no processo de produção da notícia (VIZEU, 2005).Entendemos que essas categorias, muito mais que operadores jornalísticos são na verdade complexas operações/construções nas quais o jornalismo produz a construção do real: de “atualidade”, de “objetividade”, de “interpelação”, de “leitura” e “didático”.

Na operação/construção da atualidade o jornalismo, em particular, o gênero telejornal, é na essência o “discurso da atualidade”. Não da atualidade cronológica, já que entre o momento do acontecimento do fato e a notícia temos um interregno 
“mediado” pelo telejornal, mas da "atualidade do noticiário televisivo”. Mesmo um evento transmitido ao vivo em “tempo real” se submete ao tempo e à formatação do telejornal: há um recorte sobre a realidade (pelo plano da tomada, pela forma de enquadramento, etc).

A atualidade é um vínculo central que se estabelece entre a audiência e o jornal. A ausência desse fator tornaria o telejornal obsoleto uma vez que não haveria o interesse do público em assistir o que já é conhecido, o que não é atual. Por isso, a preocupação constante no telejornalismo em apresentar qualquer notícia como se estivesse ocorrendo no momento da apresentação do noticiário.

A trabalhar com a atualidade observamos que na cobertura do dia a dia do Recife os jornalistas da TV Tribunal e da TV Jornal têm uma preocupação constante com as matérias que estão mais próximas das comunidades da periferia da cidade. Dentro desse contexto, a questão da falta de segurança, da violência urbana, assaltos, crimes, entre outros fazem parte da pauta diária dos dois noticiários.

O depoimento da editora 1, da TV Jornal, enfatiza esse aspecto: "Prefiro abrir o jornal com matérias fortes..., polícia que chama mais audiência”. No telejornal “Cotidiano”, da TV Tribuna, o quadro não é muito diferente. Já pela manhã a agenda do dia, as matérias que os repórteres devem fazem na externas (reportagems realizadas na rua) estão normalmente vinculadas aos acontecimentos que dizem respeito a violência: crimes, assassinatos, estupros, etc.; denúncias e reclamações da comunidade. A questão da violência fica bem claro no alerta que a apuradora faz logo cedo pela manhã na redação: “Tem um caso de estupro no Pacheco... (bairro periférico do Recife)”. Ou seja, é preciso ir atrás porque é um tipo de acontecimento que faz parte da agenda cotidiana moradores do Recife. .

Os telejornais acabam enfatizando um dos aspectos que constitui o dia da cidade que é a violência, deixando de lado outros que fazem parte do seu cotidiano da como a cultura, a política e economia. É como se outras atividades, outros acontecimentos como a questão do emprego, da educação, da habitação não fizessem parte do dia a dia do Recife. Nesse sentido, o enquadramento dos noticiários contribui para a construção de uma cidade em que a violência é a sua marca.

Outra operação que contribui para a construção social da realidade, para construção das cidades do telejornalismo é a objetividade. A preocupação é garantir 
que o que está sendo relatado, apresentado no telejornal é verdadeiro. As empresas jornalísticas e os jornalistas apresentam-se como detentores autorizados do poder de ordenação do mundo. Ou seja, ambos se constituem assim dispositivos de acreditação ou de autorização. No entanto, ao contrário de outros dispositivos de acreditação (professores, padres, médicos, políticos, etc.), os dispositivos da informação jornalística procedem de modo informal: tendem a fundamentar a sua força através do apelo à mediação entre a realidade e a audiência.

Com a finalidade de mostrarem que estão preocupados com a objetividade dos fatos, o telejornal “Cotidiano” e o “TV Jornal Meio-Dia” procuram o tempo todo estabelecer um “distanciamento” em relação aos acontecimentos que fazem parte da cobertura diária. A intenção é mostrar que os noticiários são fiéis a realidade, um espelho do real. Isso é reforçado pelos jornalistas dos dois noticiários que nas entrevistas foram categóricos ao afirmarem que as noticías que elaboram são um reflexo desinteressado dos acontecimentos, não admitindo a possibilidade de construções na mediação entre os fatos e as notícias. É como se as notícias não fossem submetidas a um complexo processo de seleção, produção e apresentação, não efetuasse uma série de recortes sobre os acontecimentos que vão ser apresentados nos telejornais dentro das regras, normas, cultura e linguagem do campo do Jornalismo..

Nesse sentido, o jornalista, produtor do discurso realista, situa-se no mesmo plano do artista realista (BARTHES, 2000).Quando confrontado com seu conceito de verdade o jornalista se coloca tal como o artista plástico, que se considera infalível não pela segurança das suas perfomances, mas pela autoridade da sua competência. É ele quem conhece o código, a origem, o fundamento, e quem se assume, assim, como assegura, testemunha e autor da realidade.

Ainda dentro do processo de construção social da realidade no Jornalismo, da construção das cidades do telejornalismo temos a chamada operação/construção de interpelação. O noticiário televisivo mostra-nos várias maneiras pelas quais a gramática da produção procura construir um vínculo ativo com a recepção. Os telejornais analisados procuram estabelecer com seus usuários determinadas ações que classificamos como ações de captura, construídas semanticamente pelos jornalistas, que tratam de torná-los imaginariamente presentes no interior do próprio telejornal.

Um dos exemplos é o uso do pronome pessoal nós que busca fazer da 
audiência uma espécie de co-participante do telejornal. Isso é muito comum quando o locutor/apresentador recorre ao: Nós vamos ver, Vamos conferir, etc. O telespectador é convidado a assistir determinada notícia como se estivesse na sala da casa do apresentador.

Há também outros momentos, no desenrolar do telejornal, que o apresentador deixa sua posição de um ventríloquo dos fatos e assume, invariavelmente, o papel de enunciador, em que estabelece uma conversa com o telespectador por causa de falhas técnicas ou quando se faz necessário chamar um repórter ao vivo:

-João da Silva tem mais detalhes sobre o que aconteceu....;

-Tivemos um pequeno problema técnico. Voltamos agora com a repórter Helena Regina que tem mais informações sobre determinado fato.

Além desses ainda há outros momentos em que o telespectador é interpelado no jornal televisivo. Vejamos algumas dessas operações:

-Olha...(quando é solicitada a quem assiste atenção ao que é dito);

-Veja agora...(ordenando ao telespectador que permaneça atento ao que está por vir na edição do telejornal).

\section{A LEITURA DAS CIDADES}

Em ambos os telejornais observamos que no processo de apresentação das notícias há uma preocupação ao interpelar a audiência de uma certa carga dramática no sentido de reforçar os aspectos que fazem parte do cotidiano das pessoas, da agenda delas, em particular, a preocupação com a violência. Ao procurar estabelecer essa cumplicidade com a audiência os noticiários procuram de certa forma enfatizar a cultura do medo: a rebelião no presídio, os crimes na periferia, entre outros.

O depoimento da editora 1, do noticiário “Cotidiano”, sobre a preparação das matérias que vão entrar no noticiário aponta para isso: “...vamos mostrar em breve o sentimento de pânico vivido no Recife, que hoje é uma das cidades mais violentas do País...”. É nesse momento que são mobilizadas o que denominamos de operação/construção de leitura.

Por isso, nas manchetes e nas notícias os telejornais procuram apresentar temas que pressupõem serem compartilhados com a audiência, que fazem parte da sua memória coletiva, da enciclopédia de quem assiste aos telejornais (ECO,1986). 
"Velhos cardápios" do cotidiano das cidades são oferecidos como se fossem novos pratos que contribuem para construir as cidades do telejornalismo: violência, crime, insegurança, medo, etc. É que o que fazem as editoras-chefe ao organizarem o espelho (ordem de entrada das matérias nos jornais televisivos).

Por fim um dos últimos operados mobilizados pelos jornalistas na construção das cidades do telejornalismo são os didáticos. Os jornalistas, de uma maneira geral, têm uma preocupação didática com relação à audiência. Isso é trabalhado desde os tempos da universidade até o dia-a-dia da redação. No que diz respeito ao mundo acadêmico, o livro de Paternostro: O Texto na TV : Manual de Telejornalismo, adotado pela maioria dos cursos de jornalismo do Brasil é um exemplo disso.

No capítulo que trata do texto coloquial, a autora diz que a tevê tem a obrigação de respeitar o telespectador e transmitir a informação em uma linguagem coloquial e correta. Ela explica que quem assiste ao telejornal só ouve o texto uma vez, por isso deve ser capaz de captá-lo, processá-lo e retê-lo instantaneamente. Não há uma segunda chance.

\footnotetext{
“Se o telespectador se desligar, não há desculpas: o erro foi nosso. Quanto mais as palavras (ou o texto como um todo) forem 'familiares' ao telespectador, maior será o grau de comunicação. As palavras e as estruturas das frases devem estar o mais próximo possível de uma conversa. Devemos usar palavras simples e fortes, elegantes e bonitas, apropriadas ao significado e à circunstância da história que queremos contar” (PATERNOSTRO, 1999, p. 78-85).
}

A autora antiga profissional da Rede Globo de Televisão, onde trabalhou como editora-chefe de um jornal de Rede e chefe de redação da Globo News, canal de notícias da tevê paga, hoje na função de assessora da direção da empresa sabe bem do que está falando.

O Manual de Telejornalismo da Rede Globo assume um ar professoral ao explicar como o telespectador, a audiência deve ser tratada: 
financeiros, etc. Tanto o repórter - na hora de colher as informações como o redator, na hora de escrever o off , a cabeça da matéria deve ser humilde o suficiente para perguntar, pesquisar e simplificar (...) É preferível sermos tachados de professorais por uma elite de escolarização a não sermos entendidos por uma massa enorme de telespectadores comuns" (MANUAL DA GLOBO DE TELEJORNALISMO, Central Globo de Jornalismo, 1986, p.23-24).

Dezesseis anos depois, o "Novo Manual de Telejornalismo da Rede Globo” (2001?) não foge muito das recomendações do primeiro na sua preocupação com a audiência. Segundo o manual, toda informação deve ser precisa, cada imagem ou cada palavra escolhida criteriosamente, sob pena de distorcer os fatos e confundir o telespectador:

"A nossa honestidade e ética podem ser involuntariamente comprometidas por imprecisões que levem ao telespectador a nos confundir com praticantes de um jornalismo tendencioso e irresponsável...”(NOVO MANUAL DE TELEJORNALISMO DA REDE GLOBO, no prelo).

O Manual de Telejornalismo do SBT também segue a mesma linha ao tratar à audiência:

\footnotetext{
“Nada é mais absurdo em televisão do que ouvir um repórter ou apresentador falando como se estivesse lendo um boletim de ocorrência numa delegacia de polícia ou mesmo um trecho de um relatório econômico. Funcionários do governo e acadêmicos em geral adoram estes termos complicados, que parecem funcionar como uma chave em um círculo fechado. Nossa função é decifrar esses jargões e passar tudo para uma linguagem de massa, que possa ser entendida por todas as pessoas que estiverem vendo o noticiário" (MANUAL DE TELEJORNALISMO DO SBT, não publicado).
}

Nos dois telejornais analisados, de um modo geral, podemos observar que os jornalistas (depoimentos das editoras 1 e 2 dos noticiários), apesar de saberem da existência dos manuais, não fazerem referência a eles como guias, como roteiros na 
elaboração das notícias. Acreditamos um dos fortes motivos para essa "postura” deve se ao fato de que as normas contidas nos manuais já fazem parte das rotinas das empresas, que as regras. As normas e dicas indicadas, de uma certa forma, já fazem parte da chamada cultura profissional e os jornalistas não chegam a perceber que não deixam de ser estratégias mobilizadas pelas empresas não só com o objetivo de contribuírem para o "bom andamento” do processo de produção da notícia, mas para estabelecerem também o que entendem por notícia..

Com relação aos manuais, Fausto Neto (1991) explica que eles contribuem para condicionar os procedimentos de leitura do campo da recepção, estruturando-a, segundo certas regras. Isto é, o leitor - ou no sentido mais geral, o receptor dos suportes de comunicação - é alguém construído no próprio processo de produção jornalística.

Essa operação didática é uma preocupação constante dos telejornalismo. Durante a investigação observamos que os jornalistas procuram usar textos mais coloquiais, expressões de mais fácil entendimento para audiência que eles se dirigiam para facilitar o entendimento das notícias. Na questão da violência há a preocupação em tentar mostrar a audiência de uma forma didática os fatos procurando esclarecer. de uma forma professoral suas causas.

Na pesquisa que realizamos idenficamos pistas que apontam para a construção da cidade do Recife como um lugar inseguro, onde a violência é presença constante. Com certeza são necessárias novas investigações e outras pesquisas sobe o tema. No entanto, entendemos que na medida que os dois telejornais estabelecem uma trama de fatos diárias onde o medo e a violência são uma constante, acabam contribuindo para a construção de uma Recife onde o medo e a insegurança são uma constante.

Consideramos que a diversidade social, cultural e econômica da cidade não se restringe só a esses dois aspectos. Dentro desse contexto, os noticiários contribuem para reforçar uma cultura do medo e "status quo" do Recife como uma cidade refém da violência. Refletir sobre essa perspectiva é central para entendermos a vida nas cidades e as cidades na contemporaneidade. As cidades do telejornalismo como um lugar de identidades, comportamentos, hábitos e afetos.

Como bem observa Wolton (2004), os noticiários televisivos funcionam como 
como um "laço social”. Segundo o autor os laços primários que dizem respeito à família, à vizinhança, à solidariedade de classe, à pertinência religiosa tornam-se cada vez mais distantes resultando numa fragilidade nas relações entre a massa e o indivíduo, entre a massa e as pessoas. É nessa ausência de um espaço sociocultural entre a experiência do indivíduo e do coletivo que se situa o interesse pela televisão. Ela funcionaria como um laço estruturante.

Compartilhamos com o esclarecimento do autor que não se trata de afirmar que a televisão cria o laço social, seria cair num determinismo tecnológico, mas que num período de grande mudança, de profundas rupturas sociais e culturais, de falta de referências, a televisão continua sendo um dos laços sociais da modernidade. Com certeza, não é o único, mas tem uma força muito grande em função de sua visibilidade e popularidade.

É como se os telejornais criassem um outro Recife, uma “comunidade imaginada” construída pelos telejornais. Isso porque homens e mulheres que circulam pela cidade, vivem na cidade e nunca vão se conhecer, nunca se encontrarão e nunca ouvirão falar da maioria uns dos outros terão em mente através dos noticiários terão em mente uma imagem de comunhão (ANDERSON, 2005).

É o que de certa forma ocorre numa dimensão mais ampla no Brasil nas transmissões dos grandes eventos midiáticos com a copa do mundo e as eleições.as cobriram passo a passo a cerimônia que aconteceu em Brasília. Naquele momento as milhões de pessoas que assistiam à televisão faziam parte de um grande laço do País que mostrava um pertencimento a uma Nação chamada Brasil.

Elas sabiam que naquele instante, em outras cidades, e em outros Estados, cidadãos que eles provavelmente nunca encontrarão são brasileiros que nem ele. $O$ telejornalismo ocuparia um "lugar de referência” (VIZEU; CORREIA, no prelo). Acreditamos que essa discussão pode contribuir para pensarmos a função social do telejornalismo nas sociedades democráticas. 


\section{REFERÊNCIAS BIBLIOGRÁFICAS}

ANDERSON, B. Comunidades imaginadas. Lisboa : Edições 70, 2005.

BARTHES, R. S/Z : uma análise da novela sarrasine de Honoré de Balzac. Rio de BERGER, P. T., LUCKMANN, T. A construção social da realidade. 12. ed. Petrópolis : Vozes, 1995. p.147.

BOURDIEU, P. Sobre a televisão. Rio de Janeiro : Jorge Zahar, 1997.

CASETTI, F, CHIO, F. di. Análisis de la televisión : instrumentos, métodos e prácticas de investigación. Barcelona : Paidós, 1999,

CHANDLER, D. Notes on the construction of reality in tv news programmes. Disponível em <htpp://www.aber.ac.uk/media/Modules/TF33120/news.html. Acesso em: 21 nov. 2005

CORCUFF, P. As novas sociologias : construções da realidade social. Bauru : Edusc, 2001.

GOMIS, L. Teoria del periodismo : cómo se forma el presente. México : Paidós, 1991.

HALL, S. The narrative construction of reality. Disponível em <htpp://www.centreforbook.culture.org/context/no10/hall.html. Acesso em: 21 nov. 2005

MANUAL DA GLOBO DE TELEJORNALISMO. Central Globo de Jornalismo. Rio de Janeiro : Globo, 1986.

McCOMBS, M. E, SHAW, D. L. The evolution pof agenda-setting : twenty five years in the markeplace ideas. Journal of Communcation, v. 43, n. 2, p.58-67,1993. p.58-67.

NOVO MANUAL DE TELEJORNALISMO DA REDE GLOBO. Central Globo de Jornalismo.Rio de Janeiro : Globo [2001?]. No prelo.

PARK, R. A notícia como forma de conhecimento : um capítulo da sociologia do conhecimento. In: STEINBERG, C. (org.). Meios de comunicação de massa. São Paulo : Cultrix, 1972.

PATERNOSTRO, V. I. O texto na tv : manual de telejornalismo. Rio de Janeiro : Campus, 1999.

PENA, F. Teorias do jornalismo. São Paulo : Contexto, 2005. 
PEREIRA, M. I. D. As representações sociais do Recife: as práticas jornalísticas e os estereótipos. Recife : Programa de Pós-Graduação em Comunicação Social/Departamento de Comunicação, 2006. 26p. (Conselho Nacional de Desenvolvimento Científico e Tecnológico - PIBIC). Projeto em andamento.

PNAD 2002. Pesquisa Nacional por Amostras de Domicílio. IBGE. Disponível em http://www.ibge.gov.br/home/estatistica/populacao/trabalhoerendimento/pnad2002/defa ult.shtm. Acesso em 27 de julho de 2005

RODRIGUES, Adriano Duarte. O discurso mediático. Lisboa, 1996, mimeo.

SCHUDSON, M. The sociology of news. News York : Norton, 2002.

Discovering news : a social history of American newspapers. New York : Basic Books, 1978.

THIOLLENT, M. Crítica metodológica, investigação social e enquete operária. 3.ed. São Paulo : Polis, 1982.

TUCHMAN, G. Makinf news : a study in the construction of reality. New York : Free Press, 1980.

TRAQUINA, N. Teorias do jornalismo. Florianópolis : Insular, 2004.

VERÓN, E. Construir el acontecimiento. Barcelona : Gedisa, 1995.

VIZEU, A., CORREIA, J.C. A construção do real no telejornalismo: do lugar de segurança ao lugar de referência. In: VIZEU, A. A sociedade do telejornalismo. Petrópolis : Vozes. (2008?) No prelo.

VIZEU, A. Telejornalismo: cotidiano e lugar de segurança. ENCONTRO NACIONAL DOS PESQUISADORES EM JORNALISMO, 3, 2005, Anais... Florianópolis : UFSC, SBPJor, 2006, p. 1-17. 1 CD.

VIZEU, A. O lado oculto do telejornalismo. Florianópolis : Calandra, 2005.

As representações sociais do Recife no caso dos telejornais locais. Recife : Programa de Pós-Graduação em Comunicação Social/Departamento de Comunicação, 2005-2006. 26p. (Conselho Nacional de Desenvolvimento Científico e Tecnológico PIBIC). Projeto em andamento. 
Decidindo o que é notícia : os bastidores do telejornalismo. 1.ed. Porto Alegre : EDIPUCRS, 2000.

WANDERLEI, L. C. As representações sociais de Pernambuco nas notícias dos telejornais locais: constrangimentos organizacionais, rotinas e cultura profisssional. Recife : Programa de Pós-Graduação em Comunicação Social/Departamento de Comunicação, 2006. 26p. (Conselho Nacional de Desenvolvimento Científico e Tecnológico - PIBIC). Projeto em andamento.

WOLTON, D. Elogio do grande público. São Paulo : Ática, 1996. 